\title{
EL VALOR DEL PASADO. CANON Y CRÍTICA EN LA HISTORIOGRAFÍA RECIENTE SOBRE EL CINE ESPAÑOL BAJO EL FRANQUISMO
}

\author{
Jorge Nieto FerRando ${ }^{1}$ \\ Universitat de Lleida
}

\begin{abstract}
El objetivo del presente artículo es analizar la inclusión en el canon cinematográfico español en las últimas dos décadas de ciertas películas producidas bajo el franquismo. Se parte de la consideración de que la lista de películas relevantes está sujeta a la perspectiva desde la que se aborda el cine, ya sea la crítica, el análisis o la historia, así como a los paradigmas que críticos, analistas e historiadores suscriben y el repertorio sobre el que trabajan. El canon es abordado aquí como un problema fundamentalmente historiográfico. Así, tras analizar la literatura cinematográfica sobre el franquismo, se demuestra cómo la acotación del repertorio, la búsqueda de la especificidad e identidad del cine español, la limitación del peso del contexto, la superación de la dicotomía cine franquista/cine disidente o la atención a la puesta en forma y a los vínculos de las películas con la cultura popular, han contribuido a considerar relevantes títulos que anteriormente pasaban desapercibidos.
\end{abstract}

Palabras clave: Cine español; franquismo; canon cinematográfico; historiografía del cine; crítica cinematográfica.

\section{THE VALUE OF THE PAST. CANONS AND CRITICISMS IN RECENT HISTORIOGRAPHY ON SPANISH CINEMA DURING THE FRANCO ERA}

This article aims to analyse the inclusion in the Spanish film canon during the last two decades of certain movies produced under the Franco regime. The article examines the list of relevant films by referencing them against the diverse perspectives from which cinema is approached, be it critique, analysis or history, as well as to the paradigms that critics, analysts and historians adhere to and the repertoire they work in. Here the canon is addressed as an issue that is mainly historiographical. Thus, after analysing the cinematographic literature on the Franco Era, the article shows how the boundaries of the repertoire, the search for the specificity and identity of Spanish cinema, the limiting aspects imposed by the (political) context, the overcoming of the dichotomy between pro-Franco cinema/dissident cinema, the attention to the mise-en-scène and to the movies' links with popular culture, have all contributed to allow these films that had previously gone unnoticed to be regarded as relevant.

Key words: Spanish cinema; Franco Era; film canon; film historiography; film criticism.

Cómo citar este artículo / Citation: Nieto Ferrando, Jorge (2017): "El valor del pasado. Canon y crítica en la historiografía reciente sobre el cine español bajo el franquismo". En: Archivo Español de Arte, vol. 90, núm. 359, Madrid, pp. 287-300. doi: 10.3989/aearte.2017.19

Desde hace más de dos décadas se están produciendo movimientos importantes en el canon cinematográfico español. Un ejemplo destacado fue la publicación de Antología crítica del cine español editada por Julio Pérez Perucha², trabajo que recopiló críticas de películas, en casi todos

\footnotetext{
1 nietojordi@filcat.udl.cat / ORCID iD: http://orcid.org/0000-0003-3075-2636.

21997.
} 


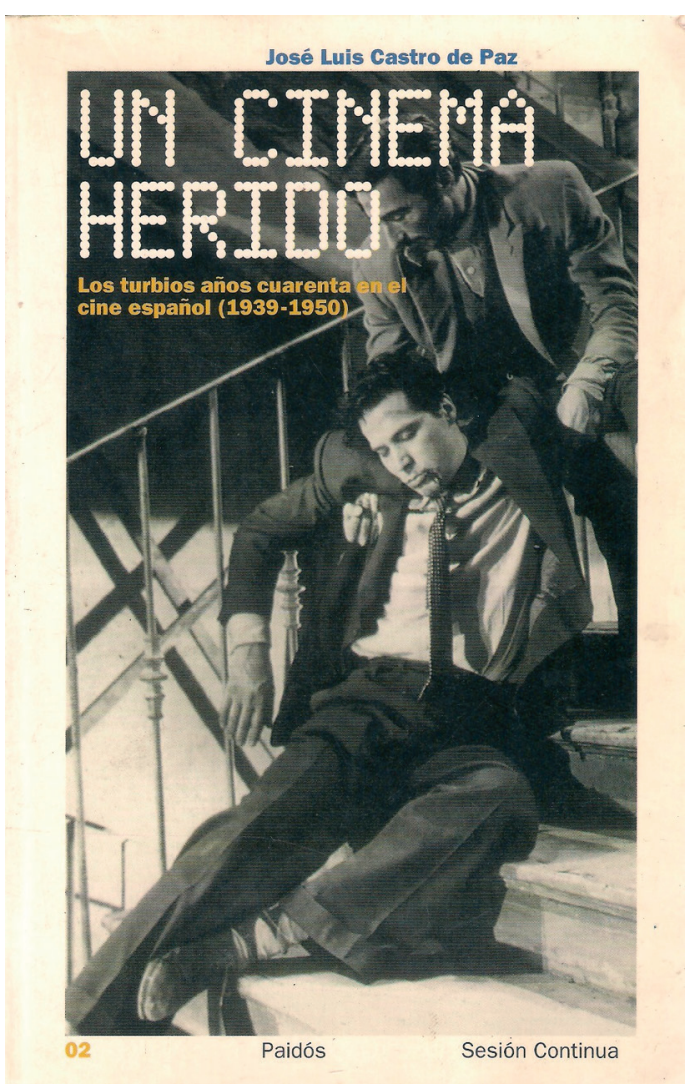

Fig. 1. Castro de Paz, José Luis (2002). Un cinema herido. Los turbios años cuarenta en el cine español. Barcelona: Paidós.

los casos trascendiendo la valoración propia de la crítica para entrar en el análisis fílmico, con la virtud de abordar títulos olvidados por considerarse irrelevantes o, en la período que nos ocupa, haberse incluido dentro del cajón de sastre de un indefinible cine franquista, al menos en comparación con la aparición del cine de García-Berlanga y Bardem a mediados de los años cincuenta y de los nuevos cines poco tiempo después. Esta publicación -junto a las de Santos Zunzunegui y José Luis Castro de Paz, los otros dos autores que encabezan la revisión de la historia del cine español- también mostraba el cariz de los cambios producidos en el canon, pues no conllevaban la sustitución de un canon por otro, sino que nuevas películas y directores comenzaban a formar parte de lo que merecía la atención de analistas e historiadores.

Resulta conveniente diferenciar de entrada dos acepciones del término "canon": por una parte, el canon como procedimiento normativo generalizado que afecta a la realización de las películas -podríamos hablar del canon en el cine clásico o de los diferentes cánones genéricos-; por otra, como conjunto de películas relevantes para una comunidad interpretativa, más susceptible a las variaciones en los criterios de pertenencia al canon-gustos estéticos, paradigmas, etcétera - y a las particularidades y cambios en dichas comunidades interpretativas. En ambos casos, y en relación con la etimología del término, el canon implica una medida, una norma, y con ello una selección de aquello que le es propio frente a lo que queda en sus márgenes externos.

El canon, ya centrándonos en su condición de elenco de obras, tiene además unas implicaciones que afectan a las políticas culturales, a los archivos cinematográficos ${ }^{3}$, a los programas docentes universitarios, a las instituciones académicas y críticas y a los mecanismos de renovación de sus miembros, a la memoria y a la identidad colectiva ${ }^{4}$, además de, entre otras muchas, a cuestiones relacionadas con la influencia o la cita entre películas. A ello hay que añadir que "not only a canon of films exists but also a canon of literature about film and a canon of film methodologies"5. No obstante, abordamos aquí el canon sobre todo como problema historiográfico, aunque esté inevitablemente ligado a estas otras consideraciones. Así, partiendo del análisis de la literatura sobre el cine bajo el franquismo publicada en la tradición académica española desde la Transición democrática ${ }^{6}$, este trabajo pretende inferir los planteamientos historiográficos

\footnotetext{
3 Wollen, 1993: 26.

4 Sullà, 1998; Pozuelo y Aradra, 2000: 33-61.

5 Staiger, 1985: 18.

${ }^{6}$ Se renuncia inevitablemente -es necesario ajustar estas páginas a unas dimensiones razonables- a abordar las relevantes aportaciones al análisis del cine bajo el franquismo de los hispanistas franceses, estadounidenses y británicos, que en muchos casos también han tratado el tema de la identidad del cine español, aunque sea desde supuestos teóricos
} 
que han permitido la entrada en la historia del cine español de ciertas películas producidas bajo el franquismo, así como de sus directores ${ }^{7}$ (fig. 1).

\section{Valor, canon e historiografía}

La cuestión del "valor" de la obra de arte es central en la estética, y ha sido introducida en el cine desde el momento en que adquiere el estatuto de arte. Puede resumirse en dos posiciones extremas: el inmanentismo y el relativismo. La primera supone que las cualidades intrínsecas de una película la convierten en valiosa o desdeñable, reduciendo cualquier otra consideración a la mínima expresión. La segunda afirma que una película siempre es valiosa para alguien en un momento concreto, de manera que el valor es relativo, incluso histórico e historiable, además de depender de la posición estética, ideológica, racial, de género, etcétera, en la que el evaluador esté situado. Puesto que incluso las posiciones inmanentes dependen de estos "determinantes", cualquier defensa de la inmanencia implica un intento de imponer los "valores" de un determinado grupo sobre los demás, y puede ser tachada de etnocentrista y a-histórica.

Laurent Jullier ${ }^{8}$ se ha aproximado al gusto cinematográfico y al valor de una película encontrando seis criterios generales capaces de regirlo: el éxito, la calidad técnica, el carácter edificante, la emoción que genera, la originalidad y la coherencia. Algunos de estos criterios son manejados por los críticos y los historiadores. Respecto al cine bajo el franquismo, son reseñables el carácter edificante, la originalidad y la coherencia. El primero supone valorar las películas por su capacidad para mostrar o instruir acerca de algo que es total o en parte desconocido, ya sea la realidad, determinadas ideologías y mentalidades, incluso la propia película, su director o el arte cinematográfico en general. Obsérvese que este criterio es útil tanto para la denominada "política de los autores" -que intenta dilucidar el estilo y el mundo personal de los directores a partir de su obra- como para las historias que analizan la representación en las películas de determinados aspectos de la sociedad o las aportaciones que desde el análisis textual buscan desenmascarar su entramado ideológico. La originalidad y la coherencia son dos criterios interrelacionados. La originalidad conlleva una ruptura parcial con el horizonte en el que aparece la película, pero sin caer en la heterodoxia incomprensible, por lo que la película también debe ser en parte coherente con este. El horizonte es móvil y variable y ambos criterios implican la comparación con el repertorio disponible de películas.

Atada a la cuestión del valor y la valoración está la del canon cinematográfico. Éste, en la acepción que nos interesa aquí, sería la lista de películas consideradas valiosas para una colectividad, susceptibles de protagonizar críticas, análisis e historias ${ }^{9}$. Por regla general, el canon provee de modelos, ideas e inspiración, legitima determinadas concepciones sobre el cine, transmite la herencia cultural y estructura el pasado. La canonización, la selección y jerarquización de las películas a partir de la parte accesible -lo que podríamos denominar repertorio- del conjunto total de películas es efectuada en base a la función atribuida al canon en un momento histórico determinado por un grupo concreto. Por tanto, el canon es histórico e historiable.

De igual manera, no hay un solo canon sino múltiples ${ }^{10}$. La perspectiva con la que se aborde el hecho fílmico y cinematográfico conduce a una jerarquización de las películas a las que afec-

\footnotetext{
e historiográficos diferentes a los que aquí se expondrán. El estudio de los puntos en común y las diferencias entre las diferentes tradiciones académicas será objeto de otro trabajo.

7 Hay que señalar que buena parte de la revisión del cine español bajo el franquismo no hubiera podido llevarse a término sin el apoyo de las diferentes filmotecas, la Asociación Española de Historiadores del Cine y la Academia de las Artes y las Ciencias Cinematográficas de España, así como de grupos y proyectos de investigación como Laboratori d’Investigació Audiovisual (LAIA), coordinado por Palmira González en la Universidad de Barcelona, o los dirigidos por Manuel Palacio desde la Universidad Carlos III de Madrid, entre otros.

82006.

9 Reformulamos aquí la definición que Sullà aplica a la literatura (2007: 12).

10 Harris, 1991: 112-113.
} 
ta y define. La primera diferencia en cuanto al canon cinematográfico reside en los tres grandes tipos de discursos generados a partir del cine: el crítico, el analítico y el historiográfico. Cada uno, con sus respectivos objetivos y funciones, está sujeto a paradigmas más o menos explícitos que pueden o no ser compartidos por los tres: una serie de supuestos sobre la naturaleza, funcionamiento y función del cine, así como los métodos que rigen la pertinencia de sus aplicaciones.

Sobre la base del paradigma, el objetivo último de la crítica es la valoración. La historia y el análisis requieren también calibrar las posibilidades de una película en relación a los supuestos historiográficos o teóricos que suscriben, pero la evaluación en principio no es una finalidad en sí misma. Los criterios de relevancia cambian en función del paradigma. Además, ya sea en la crítica, el análisis o la historia, el valor puede provenir de su reafirmación, del ajuste de la película a los supuestos que lo rigen, o, sobre todo, de su limitada puesta en cuestión, de situarse en sus límites - pero no en la incomprensible lejanía- de manera que obligue a su replanteamiento limitado o a un esfuerzo para hacer encajar la película en sus supuestos. Y lo mismo podría decirse de las críticas, análisis e historias producidas a partir de la interacción entre el paradigma y las películas, fuertemente controlados por la institución, pues como afirma Kermode ${ }^{11}$ " "what we value most $[\ldots]$ is an originality that remains close to the consensual norms".

Abordar el cine desde la crítica, el análisis o la historia ya supone un criterio de canonización, pues las películas importantes para los críticos no necesariamente lo son para los analistas o los historiadores. A ello hay que añadir los diferentes paradigmas circunscritos a cada uno de estos ámbitos. Pero además, el valor de una película para la crítica, el análisis o la historia surge de su contraste con un repertorio cinematográfico. Este puede ser definido como la parte accesible de la totalidad del cine. El repertorio permite acotar el campo de lo canonizable, y las variables que lo pautan son de muy diversa índole: desde las políticas culturales, de distribución y exhibición del cine, hasta la acción de la censura o, evidentemente, los propios paradigmas, dado que establecen el marco de los objetos susceptibles de formar parte del mismo y los criterios para su valoración, análisis o historización. Los cambios en el repertorio tienen una incidencia determinante en el canon.

Del repertorio es cribado el canon. El juicio crítico aporta algunos ejemplos interesantes de su importancia, dado que muchas veces son consideradas relevantes sobre la base del criterio de originalidad películas que tras la ampliación del repertorio se muestran deudoras de unos procedimientos ya trillados. Así sucedió a principios de los años sesenta con la recepción crítica de Los golfos (Saura, 1959), considerada por los propios críticos importante en el contexto español del momento pero superada si se comparaba con la evolución del cine internacional ${ }^{12}$. El valor, al menos si surge de la originalidad, está en función de la amplitud del repertorio con el que la película es contrastada (fig. 2).

En el caso de la historia del cine, además, hay que diferenciar la perspectiva desde la que es abordado el pasado fílmico y cinematográfico. Allen y Gomery ${ }^{13}$-también Lagny ${ }^{14}$ - distinguen cuatro tipos de historias del cine según ponen el acento en su condición estética, tecnológica, económica o social, aunque es cierto que las fronteras entre ellas se diluyen con facilidad y que determinados aspectos abordados desde una perspectiva requieren aproximaciones a otras para su adecuada comprensión. Todo ello no invalida que muchas aproximaciones al pasado prioricen un ámbito u otro. Algunas historias -las económicas y tecnológicas, por ejemplo-, además, son más cinematográficas que fílmicas. Es cierto que no desatienden a las películas, incluso que muchos de los aspectos que abordan tienen una gran relevancia en las historias del cine centradas en las películas, pero es en estas últimas, y sobre todo en las estéticas, donde el problema del canon adquiere toda su importancia.

En relación con lo apuntado podemos apreciar otro aspecto importante que también incide en la selección de películas: el enfoque autónomo o heterónomo que se imprima al análisis y a la

11 1979: 82

12 Ibáñez, 1960; Cinema Universitario, 1962.

131995.

141997. 
historia. Es decir, la historia del cine, ya sea como hecho fílmico o cinematográfico, puede tenerse a sí misma por referente prioritario o establecer puentes con marcos de referencia diferentes o más amplios. Así, podríamos tener una historia del cine como arte circunscrita al cine o que lo sitúe en relación con otras formas culturales y artísticas; una historia económica que atienda en exclusiva a la economía cinematográfica o que la ubique en relación con contextos económicos más generales; en fin, una historia tecnológica que aborde la evolución de la tecnología del cine exclusivamente o por su vínculo con otros ámbitos del audiovisual. Podría decirse que la historia social del cine es heterónoma por definición, ya que plantea de manera preferente el vínculo del cine en tanto que producto cultural con la sociedad, incluso puede convertir a las películas en documentos para el estudio de dicha sociedad. Aquí el objeto de análisis no es tanto las películas como la sociedad que "reflejan" o en la que actúan como agentes. Con todo, esta situación no es exclusiva de la historia social del cine; de hecho, podemos pensar una historia del cine como arte donde la película ejerce de documento - y agente- de unas formas artísticas propias de otras artes, y lo mismo podría decirse de las historias económicas o tecnológicas.

Finalmente, y no por obvio menos relevante, pueden ser diferentes las películas que protagonicen una historia que parte sobre todo del presente o del pasado; en otras palabras: historias que analizan determinadas películas del pasado por su repercusión o su vigencia en el presente o que las estudian por su importancia en el pasado. Las consecuencias de la primera postura puede conducir a una histórica teleológica y lineal en la que una serie de momentos decisivos - películas decisivas- acaban por confluir en la actualidad; también a historias influidas por la crítica, ya que su objeto de análisis, ciertas películas o cineastas, es planteado desde la reivindicación, el redescubrimiento o la revalorización en el presente. Hay que señalar, en cualquier caso, que algunas películas tienden a fundir pasado y presente al seguir siendo elocuentes una vez superado su inicial contexto de producción; también que cambios en el contexto de recepción -de repertorio, de paradigma, de horizonte- permiten relecturas que modifican su ubicación en la historia. El segundo toma cierta distancia -en la medida en que puede tomar distancia el historiador, siempre con su presente a cuestas- y analiza las películas por su importancia en el momento en que fueron producidas y estrenadas, con independencia de su incidencia en la actualidad. Este planteamiento tiende a iluminar las zonas en sombra que deja el foco que desde el presente en exclusiva encara el pasado, incluso permite analizar lo que ya apenas tiene repercusión.

Esta última perspectiva ha sido aplicada a enfoques heterónomos, y dentro de estos a aquellos que abordan el cine como documento sobre aspectos más generales de la sociedad. Ahora bien, la condición de documento de las películas es mantenida por las películas vivas, tanto respecto al momento de producción como a lo largo de todo el tiempo en que son elocuentes a través de la interacción con el espectador -documentan las razones de su vitalidad para públicos diferentes-, lo que puede inferirse a través de los análisis de recepción. Por otra parte, si bien las pelí- 
culas atadas a su contexto aportan por ello más información sobre este, esto no quita que también requieran ser abordadas desde planteamientos propios de la historia estética -desde el análisis de la puesta en forma, por ejemplo, vinculado por Allen y Gomery ${ }^{15}$ a dicha historia-, sin dejar de interesar por su capacidad para concretar ideologías o mentalidades de las sociedades que las producen y consumen.

Cada combinación de los parámetros apuntados, sobre todo en su concreción en las historias centradas en las películas, establece una lista de títulos relevantes a partir de un repertorio, que puede coincidir o no con otras combinaciones. De entrada esto permite afirmar la condición relativa del canon, incluso hablar de cánones más que de canon, y señalar que la cuestión clave son los parámetros de canonización antes que su resultado -el canon-, como veremos a continuación.

\section{La acotación del repertorio}

El primer eje que ha permitido la reubicación de ciertas películas y cineastas en la historia del cine español ha sido una modificación sustancial del repertorio. Si con anterioridad estaba configurado por el cine internacional, y más en concreto el europeo, los movimientos que se han gestado desde los años noventa han tendido a la comparación de las películas españolas con otras películas españolas. De esta acotación del repertorio surgen títulos valiosos que, contrastados con un corpus más amplio, pasaban desapercibidos.

Durante mucho tiempo una parte importante de la historia del cine ha puesto el acento en aquellas películas que podían entonar la producción cinematográfica española con la internacional. Esta historia hunde sus raíces en un debate recurrente sobre la necesidad de abrir las fronteras exteriores al cine español, buscar al público internacional, y las diversas estrategias para conseguirlo. En ocasiones ha superpuesto las etapas del cine europeo al español e incluso ha negado el pasado cinematográfico -un pasado irrelevante por comparación con un repertorio amplio-, la materia prima de su historia, justamente por su escasa capacidad para interesar más allá de los Pirineos ${ }^{16}$. Estas historias tienen a su favor que las fronteras apenas han podido contener la avalancha de títulos extranjeros que ya en la época analizada inundaban las pantallas españolas, tampoco paradigmas que permitían la crítica, el análisis o la historia del cine desarrollados para otros repertorios, y con ello las comparaciones son inevitables.

Puede afirmarse que el grado de coherencia estética de la producción española respecto a las vicisitudes de la europea ha sido un criterio de valor para esta historia del cine español; de ahí que hayan sido sugeridos ciertos vínculos con el neorrealismo italiano de algunas películas de los años cincuenta, se preste atención a las propuestas entonadas con los nuevos $\operatorname{cines}^{17} \mathrm{o}$ a ciertos directores singulares con resonancia internacional como Bardem, García-Berlanga o Saura. Pero esta historia del cine español ha olvidado los géneros y al cine underground, fácilmente medibles en relación con otros repertorios. El western, por ejemplo, abrió las fronteras e incluso disfrutó de una importante repercusión internacional. El olvido del cine marginal muestra, además, que este criterio es aplicado solo al cine sujeto a los cauces institucionales de producción, distribución y exhibición, cuando puede apreciarse ya a finales de los años sesenta y principios de los setenta una producción cinematográfica independiente entonada, aunque en condiciones mucho más precarias, con la vanguardia europea desde el punto de vista estético y político.

Ahora bien, la acotación del repertorio en las nuevas propuestas historiográficas no ha supuesto abandonar totalmente la equiparación internacional. Así sucede con la búsqueda de trazos de modernidad en el cine español de los años cuarenta ${ }^{18}$ o cincuenta ${ }^{19}$. Castro de Paz, por ejem-

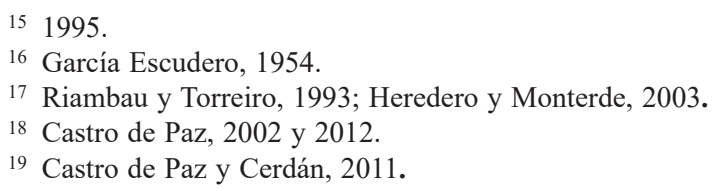

19 Castro de Paz y Cerdán, 2011. 
plo, considera que hay cierta tendencia en las comedias de principios de los años cuarenta a romper con la ilusión de la ficción, fenómeno ligado a "algunos de los populares espectáculos matrices de nuestro cine, pero es curioso observar cómo esta visibilidad del mundo de la representación, esa moderna y antitrasparente voluntad de no creerse sus propias ficciones [...] solo será retomada con igual intensidad por el cine norteamericano después de la Segunda Guerra Mundial -piénsese [...] en las llamativas semejanzas narrativas de $\mathrm{El}$ destino se disculpa y iQué bello es vivir! [...]-" 20. La consideración de moderno -inferida por contraste respecto al cine internacional- a lo anteriormente visto como antiguo o desfasado es uno de los procedimientos frecuentes de revalorización y reubicación en el canon. Pero se produce un cambio importante: el valor ya no surge del reflejo que pueda encontrarse de las principales cinematografías foráneas en la española, sino que, desde el análisis de la especificidad del cine español, se sugieren algunos procedimientos formales y narrativos equiparables a los empleados en otros cines (fig. 3).

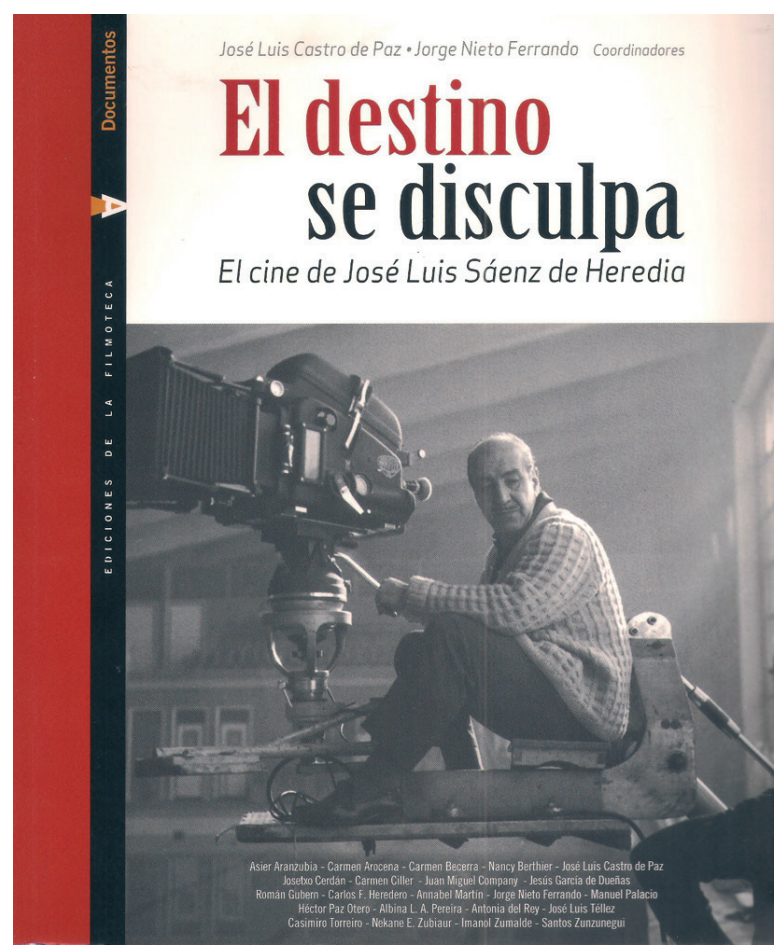

Fig. 3. Castro de Paz, José Luis/Nieto Ferrando, Jorge (eds.) (2011): El destino se disculpa. El cine de José Luis Sáenz de Heredia. Valencia: Ediciones de la Filmoteca.

\section{La especificidad}

Las nuevas tendencias historiográficas consideran que el punto de partida de la historia del cine español son los parámetros económicos, sociales y, en especial, los culturales que determinan su existencia. Estos impiden las comparaciones en términos cualitativos con otras cinematografías, dado que pueden regirse por parámetros diferentes. Tal como afirma Pérez Perucha, "el cine español [...], como cualquier otro, no es ni bueno ni malo; es, simplemente, particular, concreto y específico"21. Para el autor, un aspecto valioso de los cines nacionales es su capacidad para reelaborar las tradiciones culturales y populares que los nutren.

Zunzunegui ${ }^{22}$ precisa más este planteamiento al afirmar que la identidad del cine español debe buscarse en las formas que permiten unos estilos propios, heredadas, asimiladas, revitalizadas o transformadas a partir de "una serie de formas estéticas propias en las que se ha venido expresando históricamente la comunidad española" 23 , muchas de ellas de raigambre popular. La incidencia de otros estilos foráneos conduce al mestizaje sobre la base de este sustrato autóctono. De ahí que las comparaciones sean necesarias, pero no tanto con el objeto de evaluar el nivel de sintonía y originalidad respecto a la producción internacional, sino para apreciar aquellas estra-

\footnotetext{
20 2002: 117.

21 1992: 10 .

22 2002: 11-24.

23 2002: 14.
} 
tegias narrativas y representativas asimiladas y refundidas en el cine propio. En su opinión, dicho sustrato ha conducido al cine a una profunda estilización que se desvía del realismo, donde puede apreciarse la influencia del esperpento, la astracanada, el sainete, el "popularismo casticista" o el mito.

En lo referente al cine bajo el franquismo, los títulos considerados esenciales por el autor suponen una modificación parcial del canon: junto a las películas surgidas de la colaboración de Azcona con Ferreri y García-Berlanga y Los golfos, El espíritu de la colmena (Erice, 1973) o Furtivos (Borau, 1975), incluye, entre otras, La torre de los siete jorobados (1944), Domingo de Carnaval (1945), El crimen de la Calle Bordadores (1946), de Neville; Embrujo (1947), de Serrano de Osma; Vida en sombras (1948), de Llobet-Gràcia; Condenados (1953), Orgullo (1955) y Fedra (1956), de Mur Oti; Sierra Maldita (1954), de Del Amo; o El extraño viaje (1964), de Fernán-Gómez. Zunzunegui deja al margen, sin embargo, todo el Nuevo Cine Español, central en las historias que contrastan el cine español con repertorios amplios, aunque lo abordará en su trabajo sobre los años sesenta sometiéndolo a "la valoración global del cine producido en este lapso temporal a partir de nuevas hipótesis interpretativas que eviten el hacer del NCE una figura que se recorte sobre un fondo más o menos indiferenciado" 24 .

Si ampliamos el panorama al cine de los años cuarenta y los cincuenta presentado en los trabajos de Castro de $\mathrm{Paz}^{25}$ y Castro de Paz y Cerdán ${ }^{26}$, vemos que la nómina de películas consideradas relevantes también ha aumentado. Así, junto a los títulos ya mencionados y otros bien situados en el canon como Bienvenido, míster Marshall (García-Berlanga, 1953), Calle Mayor o El Pisito (Ferreri, 1958), aparecen recuperados Rojo y negro (1942), de Arévalo; El hombre que se quiso matar (1942), Huella de Luz (1942), El fantasma y doña Juanita (1944), de Rafael Gil; El destino se disculpa (1945), de Sáenz de Heredia; Un hombre va por el camino (1949), de Mur Oti; Rebeldía (1954), Los peces rojos (1955), El inquilino (1958), de Nieves Conde; o Marcelino pan y vino (1955), de Ladislao Vajda.

\section{La heteronomía y el peso del contexto}

Del punto anterior podemos inferir otro gran eje del cambio historiográfico: el tratamiento prioritario a las formas y la necesidad de hacer una historia estética del cine en cierto grado heterónoma. Ambos aspectos están situados en la evolución y los nuevos problemas que desde los años setenta interesan a la historia del cine como arte. Allen y Gomery ${ }^{27}$ consideran que la irrupción de la semiótica en el análisis fílmico en esta época supuso atender a los modos en que se produce significado en las películas; modos que pueden ser historiados. A ello hay que añadir los enfoques neoformalistas, caracterizados por relacionar las películas con otros sistemas del arte y de producción de significado, los análisis de recepción, atentos a la ubicación de la obra en cada contexto histórico, $\mathrm{o}$, finalmente, las propuestas que abordan relaciones intertextuales, entre textos fílmicos y entre textos fílmicos y no fílmicos, ya sean artísticos o no. En este ámbito puede situarse la apuesta de Joan Minguet ${ }^{28}$ por lo que denomina "enfoque culturológico": una historia del cine como arte en el marco global de los hechos artísticos y culturales. La historiografía reciente ha concretado esta afirmación en la atención a las formas de la cultura popular, y el cine revalorizado es justamente el que ha sabido amalgamar estas, apreciables en la pintura, el teatro, la literatura e incluso la música más popular.

Ahora bien, no es este tipo de heteronomía el que ha predominado en la historiografía. De hecho, buena parte del cine que no podía circunscribirse al arte - por comparación con un reper-

\footnotetext{
24 2005: 13 .

252002.

262011.

27 1995: 111-120.

28 1989: 71-73.
} 
torio internacional- ha sido analizado desde su capacidad para actuar como documento de aspectos concretos de la sociedad y la cultura, ya fuera porque lo permitía el género -el noticiario No-Do ${ }^{29}$ o la denominada "comedia del desarrollismo" 30 o por tratar cinematográficamente determinados temas -la Guerra Civil ${ }^{31}$, por ejemplo-. Si bien buena parte de las aproximaciones a estas cuestiones lo sortean con habilidad, existe el riesgo en la historia sociocultural del cine centrada en las películas de reducir sus análisis al contenido, de servirse de las películas para conocer lo que es más fácil y directamente apreciable a través de otras fuentes, de que el contexto se imponga al texto hasta determinar de antemano su sentido. Justamente de este peligro han advertido Hernández y Pérez ${ }^{32}$ o Zunzunegui ${ }^{33}$ respecto a la comedia de los años sesenta o Company $^{34}$ y Castro de $\mathrm{Paz}^{35}$ en lo relativo al cine de los años cuarenta, prejuzgados por afecto o defecto "franquistas" antes de cualquier análisis.

Ahora bien, incluso aunque el punto de partida sea el "carácter franquista" de muchas películas -entiéndase: cuyo contenido suscribe algunos de los supuestos éticos, morales o ideológicos que pululan bajo el amplio paraguas franquista-, el análisis permite apreciar la sutileza de su articulación en el plano de la expresión más allá del trazo grueso del tema. Un buen ejemplo de ello lo encontramos en el trabajo de Llinás ${ }^{36}$ dedicado al cine de Juan de Orduña. El autor aborda, entre otras cuestiones, el cine histórico que el director realizó entre 1948 y 1951 -Locura de amor (1948), Agustina de Aragón (1949) o La Leona de Castilla (1951)- en el que detecta unas particularidades recurrentes: la escena climática o epilogal con la que arrancan sus historias, el hecho de narrar acontecimientos que redundan en un conocimiento previo del espectador, tanto por referencias pictóricas como por la "historia oficial", y el borrado de todo suspense que permite centrar la atención en momentos de gran intensidad dramática por encima de los avatares de la acción. Se detiene sobre todo en el análisis del punto de vista -focalización y ocularización-, que en ciertos momentos rompe con los cánones del modelo de representación institucional, y su papel en la difusión de la ideología dominante. Llinás no niega que ciertas películas de Juan de Orduña sirvieran de vehículo de transmisión de dicha ideología dominante, ni mucho menos, sino que profundiza en su análisis para comprender cómo lo hicieron más allá de que estuvieran dedicadas a la historia, en su concepción más popular, tal como la entendía el franquismo; y lo hace sin por ello reivindicarlas, valorarlas positiva o negativamente, sin someterlas, en definitiva, al juicio crítico.

\section{Nuevos supuestos críticos y la superación de la dicotomía cine franquista/cine disidente}

Un cuarto eje en la renovación de la historiografía sobre el cine español bajo el franquismo es su intento de desvincularse de la función valorativa de la crítica. Esto también proviene en gran medida del desarrollo de nuevas metodologías desde los años setenta provenientes del estructuralismo, lo que hace evolucionar parte de la crítica hacia el análisis fílmico, donde la distinción entre lo sublime y lo vulgar no es tan relevante.

Castro de Paz y Cerdán en Del sainete al esperpento señalan que crítica e historia responden "a muy diferentes necesidades institucionales, y de discurso público, y por lo tanto no pueden asimilarse, por mucho que se confundan con más facilidad de la que sería conveniente" ${ }^{\text {"37. Sin }}$

\footnotetext{
29 Tranche y Sánchez-Biosca, 2000.

30 Huerta Floriano y Pérez Morán, 2013.

31 Gubern, 1986; Crusells, 2000; Sánchez-Biosca, 2006; Nieto Ferrando, 2008.

321993.

332005.

341997.

352002.

361983.

37 2011: 13 .
} 
embargo, a pesar de situarse en la historia, este trabajo y muchos otros de Castro de Paz contienen una clara reivindicación del cine enraizado en las tradiciones culturales españolas, y la reivindicación, el redescubrimiento o la revalorización nos permiten apreciar que en realidad, más que deshacerse de la crítica, el primer paso en la reconfiguración del canon ha supuesto un cambio en los criterios de valor que han sido aplicados a la historia. Puede afirmarse, de hecho, que un parámetro circunscrito a una crítica y una historia sociocultural del cine como el de disidencia -derivado del criterio edificante, tal como lo define Jullier ${ }^{38}$ - ha sido sustituido en un repertorio acotado por otros como el de coherencia -en relación con las tradiciones culturales propias- y originalidad -la singular habilidad con la que ciertas películas combinan estas tradiciones entre sí y con estrategias narrativas y representativas foráneas-, más propios de la historia estética.

Durante mucho tiempo los problemas con la censura y la manera de sortearlos mediante un discurso elusivo han sido valores destacables para la inclusión de ciertas películas y directores entre lo relevante desde la crítica o la historia. El problema del criterio disidencia es haber reducido buena parte de las películas que no encajaban en este a una suerte de cine franquista inanalizable o solo analizable en términos sociológicos, además de dotar a las que contemplaba de lo que Jullier denomina el "perfume del azufre": "Leyes y presiones implícitas pueden [...] orientar la recepción del producto: una prohibición que recaiga en una película puede acabar por nimbarla, por ejemplo, con un fascinante perfume de azufre, orientando el juicio de antemano, cuando no termina por determinarlo anticipadamente" 39 .

El criterio disidencia se institucionalizó a partir de la Transición, aunque surge en el debate crítico de las décadas de los cincuenta y sesenta, y la selección de películas que conlleva responde a las exigencias del momento: la necesidad de enfatizar la existencia de una lucha por la libertad de expresión, manifestada en ciertas películas, antes de la llegada de la democracia, aunque solo fuera dentro de la producción comercial, ya que apenas se tuvo en cuenta el cine opositor sin contemplaciones realizado desde el tardofranquismo en los márgenes externos de la industria. Ahora bien, la aceptación de un cine disidente -y con este el criterio disidencia en la evaluación- tuvo que imponerse sobre la más rupturista consideración de que casi toda la producción realizada bajo el franquismo era franquista. Como ha señalado Imanol Zumalde, en los años previos e inmediatamente posteriores a la muerte de Franco "hacer historia del cine español se convirtió en un modo más de contribuir a la causa antifranquista" ${ }^{40}$. Esto, junto con la irrupción de los nuevos paradigmas teóricos -la semiótica y el marxismo sobre todo-, condicionó los trabajos de los hermanos Pérez Merinero ${ }^{41}$ o Font ${ }^{42}$, que llegaron a considerar el cine disidente, necesariamente posibilista, y en concreto el Nuevo Cine Español, como una estrategia más de perpetuación de la dictadura en la que habrían colaborado muchos cineastas vinculados a la izquierda clandestina ${ }^{43}$.

A las películas seleccionadas por el criterio disidencia se le han aplicado con posterioridad parámetros de análisis propios de la historia estética; y al revés: películas escogidas por su originalidad y coherencia estética en los términos planteados por las nuevas propuestas historiográficas han acabado por ser disidentes, lo que muestra la imposibilidad de escapar del todo a la disidencia para conferir valor. Así puede apreciarse en el trato que ha recibido Neville, director reubicado en el corpus de lo considerado relevante. Castro de Paz, por ejemplo, afirma a propó-

382006 .

39 2006: 42.

40 2005: 425.

411973.

421976

43 Estos planteamientos también hunden sus raíces en la cultura de los años cincuenta y sesenta, incluso había encontrado su formulación -excediendo las fronteras del cine- en las apreciaciones de Sastre sobre el teatro imposible, aparecidas en esos momentos en la revista teatral Primer Acto en el marco del debate con Buero Vallejo sobre la relación crítica que el teatro debe mantener con la realidad. Recuérdese que para Sastre el posibilismo suponía una renuncia, la aceptación del horizonte de constricciones estéticas y políticas marcado por la censura, normalizar su existencia, casi una suerte de colaboracionismo (1960: 2). 
sito de Domingo de Carnaval que el director elabora un "programa formal de escrupulosa medi(ta)da disidencia cultural. Progresivamente desencantado del Régimen militar que había apoyado y contribuido de alguna forma a llevar al poder, conocía a la perfección qué elementos culturales podían ser entrelazados textualmente de forma aparentemente inocua y solidamente asentada en la intocable tradición artística española" ${ }^{4}$, aunque más adelante señalará que ello es debido a la influencia de la pintura de José Gutiérrez Solana en esta película ${ }^{45}$.

En cualquier caso, una vez ubicado en su lugar el criterio disidencia -sin menospreciarlo ni concederle una relevancia absoluta-, los cambios en el canon han tenido dos bifurcaciones. La primera se ha centrado en películas que muestran cierta "independencia" -es ilegítimo utilizar la palabra "libertad"- respecto al contexto político y las exigencias que este impone al cine. No es que estas películas vaguen por un limbo alejado de dichas constricciones, sino que sus imposiciones y servidumbres pesan menos que en otros directores que las asumen o se enfrentan a ellas. Tal vez por ello son películas, como las de Neville, que todavía pueden ser elocuentes en la actualidad. La segunda vía, de la que puede considerarse un antecedente el mencionado texto de Llinás ${ }^{46}$, ha comenzado a analizar el cine que no fue independiente desde los nuevos métodos analíticos y sin reivindicación alguna. No es negado el carácter franquista de muchas películas -entiéndase de nuevo: cuyo contenido suscribe algunos de los supuestos éticos, morales o ideológicos que pululan bajo el amplio paraguas franquista-, pero ello no implica eludir el análisis o reducirlo a un enfoque sociológico o contenudista. No es tan importante su elocuencia en el presente como su relevancia en el pasado, ya sea por constituirse como un modelo a seguir o lograr unas repercusiones estéticas y sociales destacadas en su momento. Se mantienen las lecturas socioculturales, pero intentando conjugarlas con las estéticas sobre la base de dar prioridad al análisis fílmico. Esta manera de analizar e historiar el cine sí que se deshace definitivamente de la crítica.

\section{Los "nuevos" autores}

Hasta los cambios historiográficos recientes el único cine de autor era el disidente política o ideológicamente -"The Spanish auteur tradition would implicitly be synonymous with antiFrancoism", señala Marvin D'Lugo ${ }^{47}$. Esto permite apreciar, de nuevo, la confluencia entre un criterio de relevancia propio, en principio, de la historia sociocultural del cine-disidencia- con otro vinculado con claridad a la estética -autor-.

Como es conocido, la noción de autor, desde su formulación en la revista Cahiers du cinéma en la década de los cincuenta, ha sido un paso importante en la dignificación del cine como arte y un instrumento esencial de canonización de ciertas películas y directores. Es cierto que la irrupción del análisis fílmico supone una ruptura con la autoría; pero también lo es que con el tiempo, y desposeída de su concepción de la fusión entre el mundo personal y el estilo propio de los directores considerados autores y de su carga cinéfila, la categoría -ahora ya solo directorcontinúa empleándose para organizar corpus de películas que después son sometidas a análisis de diverso tipo.

Los antecedentes de la vinculación entre autor y disidencia pueden rastrearse en la crítica de los años cincuenta y sesenta y llegan hasta prácticamente la actualidad. Un ejemplo lo encontramos en Las huellas del tiempo. Cine español, 1951-1961, de Carlos F. Heredero ${ }^{48}$. Las páginas que el autor dedica al desarrollo creativo del cine español en esta década están divididas en "Ciclos y géneros" (cap. 8) y "Disidencia interior" (cap. 9), donde aparecen identificados cuatro directores: Bardem, García-Berlanga, Fernán-Gómez y Ferreri. El cine disidente es cine de autor. Al cine no

\footnotetext{
44 2002: 152 .

45 2012: 271.

461983.

47 2013: 115.

481993.
} 


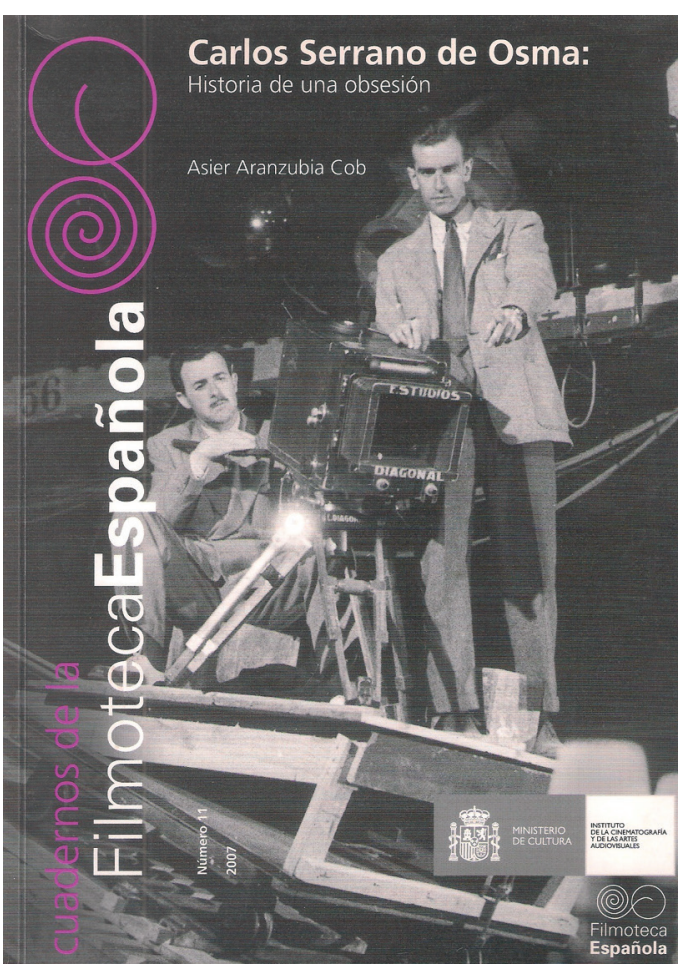

Fig. 4. Aranzubia Cob, Asier (2007): Carlos Serrano de Osma. Historia de una obsesión. Madrid: Filmoteca Española. disidente, sin embargo, se le aplica una categorización en relación con el contenido -abordan cuestiones relacionadas con la historia, la religión o la Guerra Civil- y con el caracter redundante, tanto en el contenido como en la expresión, del género -el musical, el policiaco o la comedia-. Basta comparar esta publicación con Del sainete al esperpento para percibir cómo a los anteriores se han añadido los directores Nieves Conde, Ladislao Vajda o Mur Oti, cuya inclusión ya no responde -o no responde totalmente- a su supuesta disidencia.

Es cierto que buena parte de la bibliografía sigue estando protagonizada por los mismos nombres -Buñuel, Saura, García-Berlanga, Bardem, Erice, Fernán-Gómez o Borau ${ }^{49}$-, pero desde los años noventa aparecen también publicaciones dedicadas a Benito Perojo, Nieves Conde, Ladislao Vajda, Antonio Román, Serrano de Osma, Neville, Sáenz de Heredia, Mur Oti, Vicente Escrivá o Juan de Orduña ${ }^{50}$, entre otros, cuyo cine se consideraba, aunque en ciertos casos más que en otros, demasiado atado a su contexto, incluso franquista por corporeizar algunas de las diversas ideologías que pululaban bajo el paraguas de la dictadura o simplemente ser escapistas. Los nuevos supuestos historiográficos les han permitido salir de la invisibilidad y de los análisis exclusivamente sociológicos y contenudistas (fig. 4).

\section{Conclusión}

El canon está sujeto a la perspectiva desde la que se aborda el cine, ya sea la crítica, el análisis o la historia, así como a los paradigmas que críticos, analistas e historiadores suscriben y el repertorio sobre el que trabajan. Más en concreto en lo referente a la historiografía, el canon está sometido a las diferentes aproximaciones al pasado fílmico y cinematográfico, ya sean desde la historia estética, social, económica o tecnológica, al grado de presencia del presente en este pasado o a si la historia es planteada como autónoma o heterónoma. Esto hace que el problema del canon no sean las películas que lo conforman sino los criterios de su inclusión.

La reformulación del canon del cine español bajo el franquismo se ha planteado a partir de una serie de supuestos, no exentos de contradicciones, que han llegado a configurar una suerte de paradigma historiográfico:

1. El valor de una película española, y en consecuencia sus posibilidades respecto al canon, no puede inferirse de la comparación con películas producidas en otras cinematografías, dado que estas responden a parámetros culturales diferentes. El contraste que permite decantar el valor debe producirse en relación con un repertorio más acotado.

\footnotetext{
49 Riambau, 2009: 564-607.

50 Llinás, 1997; Castro de Paz y Pérez Perucha, 2003; Coira, 2004; Aranzubia, 2007; Castro de Paz y Nieto Ferrando, 2011; Zubiaur, 2013; Rubio, 2013 o Nieto Jiménez, 2014, entre otros.
} 
2. Las películas son relevantes por su puesta en forma, por su capacidad para articular tradiciones que provienen de la cultura popular española y, siempre sobre la base de esta, hacer propias las influencias externas. El contenido temático deja de ser prioritario y se busca un mayor equilibrio con el plano de la expresión.

3. El contexto no puede ser un determinante apriorístico que impone el sentido de las películas. El análisis fílmico permite apreciar numerosas contradicciones respecto al lugar que supuestamente ocupan las películas y los directores en el sistema cinematográfico bajo el franquismo.

4. Si bien se apuesta por la separación entre crítica e historia, puede apreciarse más bien la sustitución de unos parámetros de valor por otros. Así, la disidencia y la coherencia con el cine internacional han sido en parte sustituidos por la originalidad, sobre la base de un repertorio reducido, y la coherencia con algunas manifestaciones de la cultura popular.

Ahora bien, también podemos encontrar películas que trascienden los límites que parcelan el canon. Tal como afirman Pozuelo y Aradra, "no es la supervivencia del comentario lo que permite la canonicidad, sino la supervivencia del objeto a comentarios cambiantes y movedizos" 51 . Pocos historiadores, analistas o críticos negarían esta condición en el cine bajo el franquismo a un puñado de películas, entre las que destacarían El espiritu de la colmena y Bienvenido, míster Marshall, aunque ésta tal vez comparte el privilegio con El verdugo. El consenso sería igualmente amplio respecto a Calle Mayor, Los golfos, Plácido (García-Berlanga, 1961), Nueve cartas a Berta (Martín Patino, 1967), La caza (Saura, 1966) o La prima Angélica (Saura, 1974). Puede afirmarse, de hecho, que la mayor parte de los movimientos de inclusión de películas y cineastas en el marco de lo criticable, analizable o historiable se han producido en estratos medios e inferiores del canon, manteniéndose, con alguna revisión -tal vez circunscrita al cine de Edgar Neville-, las películas que ocupan su cima, donde los puntos de acuerdo son más estables.

La clave en estos casos reside en intentar dilucidar las razones que permiten la elocuencia de estas películas, su pervivencia a los comentarios, su larga vida frente a otras atadas a su contexto o más vulnerables a las fluctuaciones canónicas. El problema puede ser abordado desde dos perspectivas interrelacionadas. En primer lugar, atendiendo a estos comentarios cambiantes mediante el análisis de la recepción, lo que nos permitiría apreciar aquellas constantes destacadas por críticos, analistas e historiadores a lo largo del tiempo. Esta aproximación debe mantener un alto grado de heteronomía, dado que dichos comentarios son deudores de parámetros culturales, estéticos y sociales que van más allá del estrecho marco del cine. En segundo lugar, y tal vez más importante, bucear en las propias estructuras de los textos fílmicos hasta encontrar aquello que permite su apertura y perdurabilidad. Volvemos entonces al dilema con el que partíamos en esta aproximación al canon cinematográfico - ¿reside el valor en lo inmanente o en lo relativo?-, aunque reformulado: ¿Existen una serie de condiciones en la inmanencia que permiten a una película sobrevivir a la relatividad?

\section{BIBLIOGRAFÍA}

Allen, Robert C./Gomery, Douglas (1995): Teoría y práctica de la historia del cine. Barcelona: Paidós.

Aranzubia Cob, Asier (2007): Carlos Serrano de Osma. Historia de una obsesión. Madrid: Filmoteca Española.

Castro de Paz, José Luis (2002): Un cinema herido. Los turbios años cuarenta en el cine español. Barcelona: Paidós.

Castro de Paz, José Luis (2012): Sombras desoladas. Costumbrismo, humor, melancolía y reflexividad en el cine español de los años cuarenta (1939-1950). Santander: Shangrila.

Castro de Paz, José Luis/Pérez Perucha, Julio (eds.) (2003): Tragedia e ironía. El cine de Nieves Conde, Orense: Concello de Ourense.

Castro de Paz, José Luis/Nieto Ferrando, Jorge (eds.) (2011): El destino se disculpa. El cine de José Luis Sáenz de Heredia. Valencia: Ediciones de la Filmoteca.

51 2000: 50 . 
Castro de Paz, José Luis/Cerdán, Josexo (2011): Del sainete al esperpento. Relecturas del cine español de los años cincuenta. Madrid: Cátedra.

Cinema Universitario (1962): "Conversación con Carlos Saura". Cinema Universitario, 16, pp. 15-29.

Coira, Pepe (2004): Antonio Román. Un cineasta de la posguerra. Madrid: Editorial Complutense.

Company, Juan Miguel (1997): Formas y perversiones del compromiso. El cine español de los años cuarenta. Valencia: Episteme.

Crusells, Magí (2000): La Guerra Civil española. Cine y propaganda. Barcelona: Ariel.

D’Lugo, Marvin (2013): “Auteurism and Spain”. En: Labanyi, Jo/Pavlovic, Tatjana (eds.): A Companion to Spanish Cinema. Malden, MA: Wiley-Blackwell, pp. 113-119.

Font, Domènec (1976): Del azul al verde. El cine español durante el franquismo. Barcelona: Avance.

García Escudero, José María (1954): La historia en 100 palabras del cine español y otros escritos sobre cine. Salamanca: Cineclub del SEU.

Gubern, Román (1986): 1936-1939. La Guerra de España en la pantalla. Madrid: Filmoteca Española.

Harris, Wendell V. (1991): “Canonicity”. PMLA, 106-1, pp. 110-121.

Heredero, Carlos F. (1993): Las huellas del tiempo. Cine español 1951-1961. Madrid/Valencia: Filmoteca Española/ Filmoteca de la Generalitat Valenciana.

Heredero, Carlos F./Monterde, José Enrique (eds.) (2003): Los "Nuevos cines" en España. Valencia: Ediciones de la Filmoteca.

Hernández, Javier/Pérez, Pablo (1993): "Un universo proteico y multiforme. La comedia costumbrista del desarrollismo". En Minguet, Joan/Pérez Perucha, Julio (eds.): El paso del mudo al sonoro en el cine Español. Vol. 2. Madrid: Editorial Complutense/AEHC, pp. 311-320.

Huerta Floriano, Miguel Ángel/Pérez Morán, Ernesto (2013): "La imagen de la España tardofranquista en las películas de Manolo Escobar". Revista Latina de Comunicación Social, 68, pp. 189-216.

Ibáñez, Enrique (1960): “Los golfos”. Documentos Cinematográficos, 2, p. 63.

Jullier, Laurent (2006): ¿Qué es una buena película? Barcelona: Paidós.

Kermode, Frank (1979): “Institutional Control of Interpretation”. Salmagundi, 43, pp. 72-86.

Lagny, Michèle (1997): Cine e historia. Problemas y métodos en la investigación cinematográfica. Barcelona: Bosch.

Llinás, Francisco (1983). "Juan de Orduña: redundancia y pasión”. Contracampo, 34, pp. 83-90.

Llinás, Francisco (1997): Ladislao Vajda. El húngaro errante, Valladolid: SEMINCI/SGAE.

Nieto Ferrando, Jorge (2008): La memoria cinematográfica de la Guerra Civil. Valencia: PUV.

Nieto Jiménez, Rafael (2014): Juan de Orduña. Cincuenta años de cine español (1924-1974). Santander: Shangrila.

Minguet Batllori, Joan (1989): "Una proposta interdisciplinar. El mètode culturològic". En: Romaguera, Joaquim/ Lorenzo, Juan Bonifacio (eds.): Metodologías de la historia del cine. Gijón: Festival Internacional de Cine de Gijón, 1989, pp. 67-73.

Pérez Merinero, David/Pérez Merinero, Carlos (1973): Cine español. Algunos materiales por derribo. Madrid: Cuadernos para el Diálogo.

Pérez Perucha, Julio (1992): Cine español. Algunos jalones significativos. Madrid: Films 210.

Pérez Perucha, Julio (ed.) (1997): Antología crítica del cine español. Madrid: Filmoteca Española/Cátedra.

Pozuelo Yvancos, José María/Aradra Sánchez, Rosa María (2000): Teoría del canon y literatura española. Madrid: Cátedra.

Riambau, Esteve (2009). "Bibliografía”. En: Gubern, Román/Monterde, José Enrique/Pérez Perucha, Julio/Riambau, Esteve/Torreiro, Casimiro (2009): Historia del cine español. Madrid: Cátedra, pp. 564-607.

Riambau, Esteve/Torreiro, Casimiro (1993): Temps era temps. El cinema de l'Escola de Barcelona i el seu entorn. Barcelona: Generalitat de Catalunya.

Rubio Alcover, Agustín (2013): Vicente Escrivá. Película de una España. Valencia: Ediciones de la Filmoteca.

Sánchez-Biosca, Vicente. (2006): Cine y Guerra Civil española. Del mito a la memoria. Madrid: Alianza.

Sastre, Alfonso (1960): "Teatro imposible y pacto social". Primer Acto, 14, pp. 1-2.

Staiger, Janet (1985): “The Politics of Film Canons". Cinema Journal, 24-3, pp. 4-23.

Sullà, Enric (1998): "El debate sobre el canon literario". En: Sullà, Enric (ed.): El canon literario. Madrid: Arco, pp. 11-34.

Sullà, Enric (2007): "El cànon literari: per a una definició operativa". Literatures, 5, pp. 9-22.

Tranche, Rafael/Sánchez-Biosca, Vicente (2000): No-Do. El tiempo y la memoria. Madrid: Cátedra/Filmoteca Española, 2000.

Wollen, Peter (1993): “Films: Why do some Survive and Others Disappear?". Sight and Sound, 3-5, pp. 26-28.

Zubiaur, Nekane (2013): Anatomía de un cineasta pasional. El cine de Manuel Mur Oti, Santander: Shangrila.

Zumalde, Imanol (2005): “Asignatura pendiente. Pequeño breviario de la historiografía del cine español”. En: Castro de Paz, José Luis/Pérez Perucha, Julio/Zunzunegui, Santos (eds.): La nueva memoria. Historia(s) del cine español (1939-2000). La Coruña: Vía Láctea, pp. 421-481.

Zunzunegui, Santos (2002): Historias de España. De qué hablamos cuando hablamos de cine español. Valencia: Ediciones de la Filmoteca.

Zunzunegui, Santos (2005): Los felices sesenta. Aventuras y desventuras del cine español (1959-1971). Barcelona: Paidós.

Fecha de recepción: 15-I-2016

Fecha de aceptación: 19-V-2016 